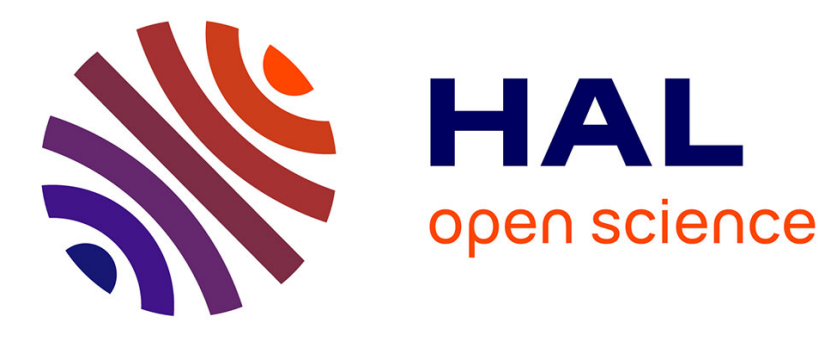

\title{
Are critical care authors publication dealers?
}

Peter Buhl Hjortrup, Chiara Robba, Emmanuel Weiss, Audrey de Jong, Julie Helms

\section{To cite this version:}

Peter Buhl Hjortrup, Chiara Robba, Emmanuel Weiss, Audrey de Jong, Julie Helms. Are critical care authors publication dealers?. Intensive Care Medicine, 2019, 131, pp.155-163. 10.1007/s00134-01905733-8 . hal-02270005

\section{HAL Id: hal-02270005 https://hal.science/hal-02270005}

Submitted on 1 Jun 2020

HAL is a multi-disciplinary open access archive for the deposit and dissemination of scientific research documents, whether they are published or not. The documents may come from teaching and research institutions in France or abroad, or from public or private research centers.
L'archive ouverte pluridisciplinaire HAL, est destinée au dépôt et à la diffusion de documents scientifiques de niveau recherche, publiés ou non, émanant des établissements d'enseignement et de recherche français ou étrangers, des laboratoires publics ou privés. 


\title{
Are critical care authors publication dealers?
}

\author{
Peter Buhl Hjortrup ${ }^{1}$, Chiara Robba ${ }^{2}$, Emmanuel Weiss ${ }^{3,4}$, Audrey De Jong ${ }^{5}$ and Julie Helms $s^{6,7^{*}}$
}

\section{Dear Editor,}

An unfeasibly large number of publications in recognized, peer-reviewed journals might reveal guest authorship, or some kind of fraud $[1,2]$. Ioannidis et al. recently reported that some scientists were indeed disproportionably hyperprolific [1]. Although asserting that they have no evidence of any fraud, Ioannidis et al., however, suggested that these authors may "have operationalized their own definitions of what authorship means" by not fulfilling several criteria established for the authorship of medical studies. The aim of our study was therefore to investigate the perception of both authorship and conflicts of interest among the most prolific authors in critical care. These prolific authors were identified by searching Pubmed for original articles, conference papers, reviews, editorials, opinion articles, and letters, published in journals with an Impact Factor of $2017>5$ in the Web of Science category CRITICAL CARE MEDICINE (ESM 1) between the 1 June 2013 and the 31 May 2018 (5 years). Of 83 most prolific authors having published more than 40 publications in the last 5 years, 78 (5 with several homonyms excluded) were sent a questionnaire by email (followed by 3 reminders) in December 2018, asking how they met the criteria of authorship and perceived barriers in publishing. The questionnaire is provided in ESM 2.

We observed a high survey participation rate of $90 \%$ (70 responses; ESM Table 1). All the responders considered their publications over the last 5 years to have changed ICU practices and patient or family management, although $12 \%$ of them considered these changes as minor. Most (86\%) considered their publications over the last 5 years as very influential. The feeling of being an

\footnotetext{
*Correspondence: julie.helms@chru-strasbourg.fr

${ }^{7}$ Service de Reanimation Médicale, Nouvel Hôpital Civil, 1, place de I'Hôpital, 67091 Strasbourg Cedex, France

Full author information is available at the end of the article
}

opinion leader did not depend on the number of publications, on the number of citations or on the seniority of the authors ( $p=0.54,0.57$ and 0.15 , respectively). Declared compliance of the authors to ICMJE criteria was unequal: $34 \%$ of the responders declared to have met all the ICMJE criteria between 76 and $100 \%$ of the time in the past 5 years, and $48 \%$ declared to have met them between 51 and $75 \%$ of the time. In line with these findings, the majority of the authors considered some criteria such as funding, data collection and general supervision not or only somewhat important. On the other hand, acquisition and interpretation of the data and drafting of the manuscript were perceived as fairly or very important by all the authors (Fig. 1). Sixty-nine percent of the responders declared that the industry had not influenced their publications at all, $24 \%$ declared it had a slight influence and only $7 \%$ some influence, while none of them declared it has had a significant influence. The number of publications was not influenced by declared conflicts of interest $(p=0.90)$.

Looking for the potential malevolent forces and trying to assess critical care author hyper-prolificity, we have questioned their integrity of authorship. We limited our questionnaire to the most prolific authors to assess the perception and practices of this selected group; the results are therefore not likely to be generalizable to all critical care authors. It has been suggested that some corresponding authors included authors with little involvement in the author list (guest authorship), while excluding others with substantial intellectual contribution (ghost authorship); Sauermann and Haeussler for example showed that among more than 12,000 analyzed articles published in PLOS, $48 \%$ of the listed co-authors did not fulfil the criteria for authorship [3]. Although our questionnaire was based on self-reported data and thereby may not reflect true attitudes, the prolific critical care authors did not seem to have succumbed to these temptations and most of the authors (82\%) declared they have met all the ICMJE criteria in more than half 


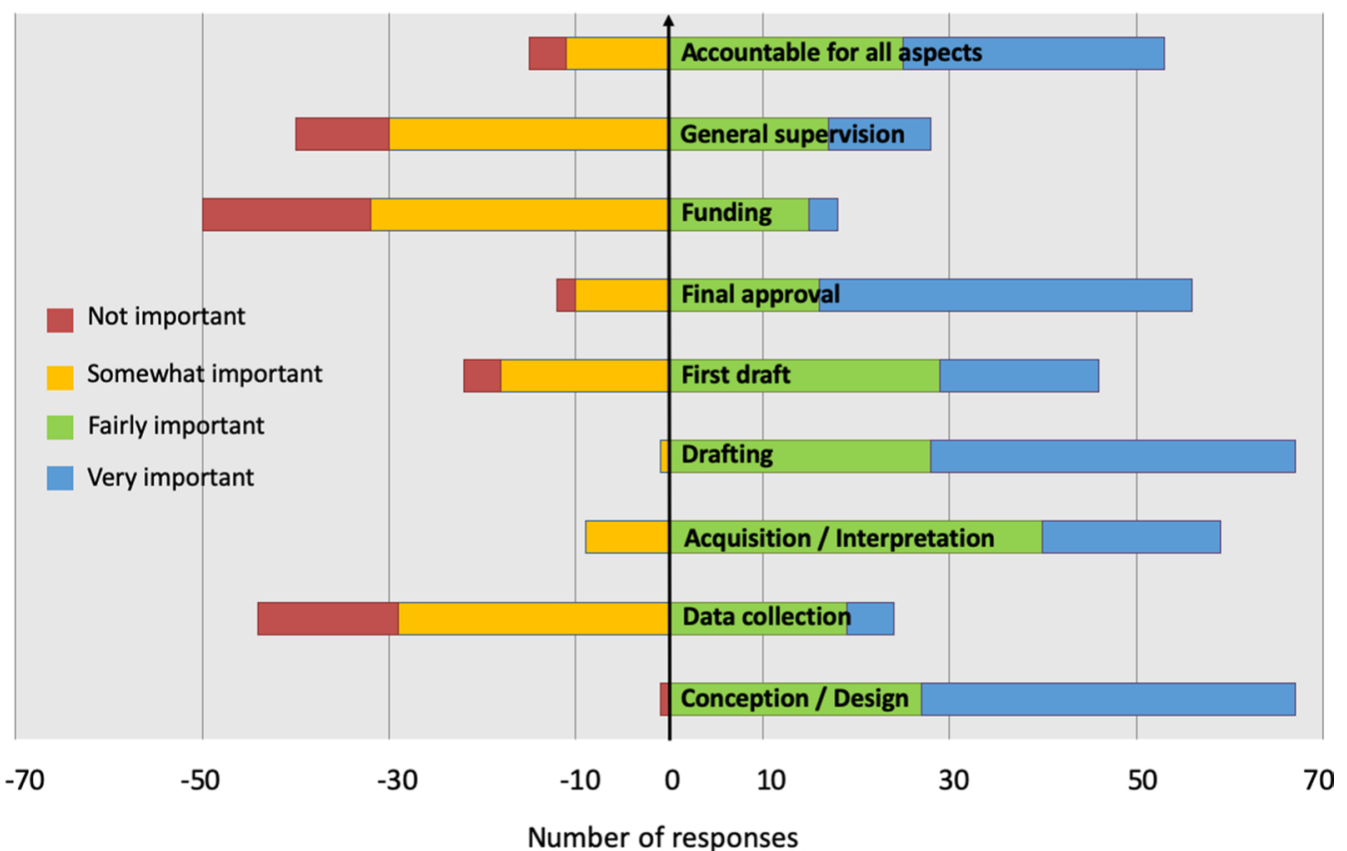

Fig. 1 Perception of International Committee of Medical Journal Editor criteria by the 78 highly prolific authors surveyed. The number of responses less than zero on the $x$-axis include "not important" and "somewhat important" criteria. The number of responses greater than zero on the $x$-axis include "fairly important" and "very important" criteria

of their articles in the past 5 years. Notably, even if nearperfection has some flaws, the (declared) non-compliance to some ICMJE criteria was not associated with a higher number of publications. A possible contributing factor to critical care not being as affected could be the high degree of clinical work amongst critical care authors compared to other medical specialties whereby publications may have the same influence on careers. Nevertheless, regardless of medical specialty, there are several factors incentivizing author prolificity: advancing careers in academic institutions and obtaining funding for future research may promote maximizing research output. These incentives risk harming both research and researchers by promoting quantitative research rather than quality research and skewing the work-life balance of individual researchers trying to meet never-ending demands. The limited funding in academic research may give rise to authorships being a valuable currency where contributions to research are paid with authorships rather than funds. This may create a double-edged sword witch on the one hand may benefit medical research by enabling well done research where funding is otherwise not feasible, but on the other hand disregarding ICMJE criteria and the true authorship.

Most of the critical care influent authors considered that their research and publications have not been influenced by industrial COI. Consistently, Zhang et al.
[4] showed no evidence of a close relationship between conflicts of interests and study results. They, however, did suggest a potential association between COI and the conclusions of the article, because of under declared COI, which we have also shown in a recent systematic review [5]. Other studies, however, alerted on the risks of industrial COI, as drug and device studies sponsored by manufacturing companies have more favorable efficacy results and conclusions than studies sponsored by other sources. Even if not sufficient, systematic compliance to COI declaration might help rely on RCT results despite the involvement of industry in some of them.

Although critical care prolific authors may not be irreproachable, it seems that our specialty is somewhat preserved from the misappropriation of authorship that may be observed in some science topics.

\section{Author details}

Department of Intensive Care, Copenhagen University Hospital, Rigshospitalet Blegdamsvej 9, 2100 Copenhagen, Denmark. ${ }^{2}$ Department of Anaesthesia and Intensive Care, Policlinico San Martino, IRCCS for Oncology and Neuroscience, Genoa, Italy. ${ }^{3}$ Department of Anesthesiology and Critical Care, AP-HP, Beaujon Hospital, Clichy, France. ${ }^{4}$ UMR_S 1149 Centre for Research on Inflammation, Inserm/Université de Paris, Paris, France. ${ }^{5}$ Department of Anesthesia and Intensive Care Unit, Regional University Hospital of Montpellier, St-Eloi Hospital, PhyMedExp, University of Montpellier, INSERM U1046, CNRS UMR, 
9214, Montpellier, France. ${ }^{6}$ Faculté de Médecine, ImmunoRhumatologie Moléculaire, INSERM UMR_S1109, LabEx TRANSPLANTEX, Centre de Recherche d'Immunologie et d'Hématologie, Fédération Hospitalo-Universitaire (FHU) OMICARE, Fédération de Médecine Translationnelle de Strasbourg (FMTS), Université de Strasbourg, Strasbourg, France. ${ }^{7}$ Service de Reanimation Médicale, Nouvel Hôpital Civil, 1, place de l'Hôpital, 67091 Strasbourg Cedex, France.

\section{Compliance with ethical standards}

\section{Conflicts of interest}

A De Jong reports personal fees from Baxter and Medtronic-Covidien, and travel reimbursements from Fresenius-Kabi, MSD France, Astellas, Pfizer and Fisher Paykel. J. Helms reports congress and travel reimbursements from Pfizer, Diagnostica Stago, MSD France, Astrazeneca and Gilead Sciences. E. Weiss reports personal fees form Baxter, MSD France and Biomerieux, and travel reimbursements from MSD France and Eumedica. The other authors have no conflict of interest to declare.

\section{References}

1. Ioannidis JPA, Klavans R, Boyack KW (2018) Thousands of scientists publish a paper every five days. Nature 561(7722):167-169

2. Marusic A, Bosnjak $L$, Jeroncic A (2011) A systematic review of research on the meaning, ethics and practices of authorship across scholarly disciplines. PLoS One 6(9):e23477

3. Sauermann $\mathrm{H}$, Haeussler C (2017) Authorship and contribution disclosures. Sci Adv 3(11):e1700404

4. Zhang L, Dai F, Brackett A, Ai Y, Meng L (2018) Association of conflicts of interest with the results and conclusions of goal-directed hemodynamic therapy research: a systematic review with meta-analysis. Intensive Care Med 44(10):1638-1656

5. Darmon M, Helms J, De Jong A, Hjortrup PB, Weiss E, Granholm A et al (2018) Time trends in the reporting of conflicts of interest, funding and affiliation with industry in intensive care research: a systematic review. Intensive Care Med 44(10):1669-1678 